\title{
TFR
}

DOSSIÊ|ENTREVISTA

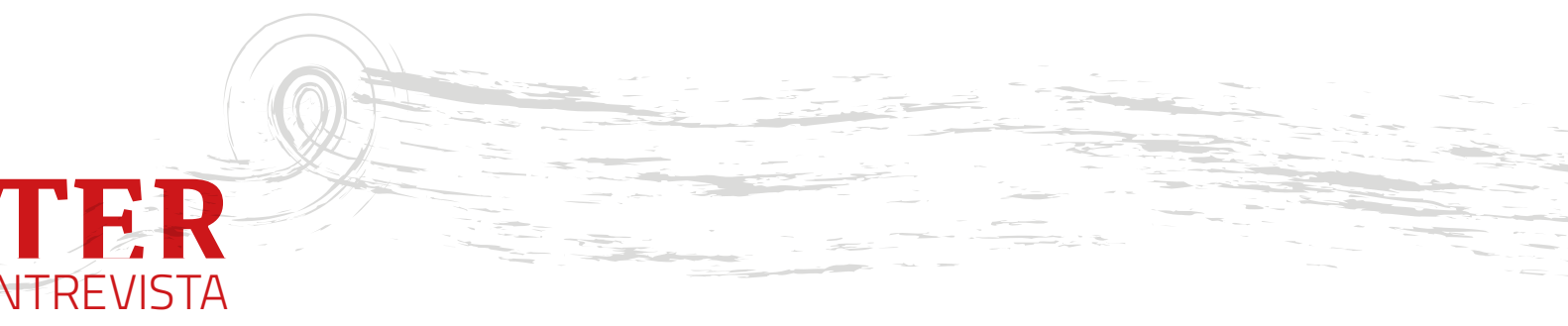

ENTRE ARTE E

ANTROPOLOGIA ENCONTRO COM

https://dx.doi.org/10.11606/ ARND SCHNEIDER ${ }^{1}$

\section{JASPER CHALCRAFT}

ORCID Robert Schuman Centre for Advanced Studies, European

\section{ROSE SATIKO G. HIKIJI}

ORcID Universidade de São Paulo, São Paulo, SP, Brasil, 05508-010

Em seu livro mais recente, Alternative Art and Anthropology: Global encounters (Bloomsbury, 2017), resenhado nesta edição da GIS, Arnd Schneider explora as intersecções entre arte e antropologia, campo que percorre já há muitos anos, mas experimentando trajetos distantes do Norte Global, conduzindo conversas com artistas na África, Butão, Chile, China, Equador, Indonésia, Japão e Filipinas. Seu interesse na colaboração com artistas vem sendo explorado há mais de duas décadas, em pesquisas de campo na Argentina (Appropriation as Practice: Art and Identity in Argentina, Palgrave, 2006), e projetos europeus, como o Programa financiado pela HERA 'Creativity and Innovation in a World of Movement' (2010 - 2012), da European Science Foundation, e o 'TRACES: Transmitting Contentious Cultural Heritages with the Arts' (2016 - 2019), financiado pelo programa Horizon 2020 da União Europeia.

Na seminal conferência "Fieldworks: Dialogues between Art and Anthropology", coorganizada por Schneider na Tate Modern, em Londres, em 2003, e disponível online (https://www.tate.org.uk/search?q=Fieldworks\&type=media), e nas coletâneas que coorganizou com Christopher Wright como Contemporary Art and Anthropology (Berg, 2006), Between Art and Anthropology (Berg, 2010), and Anthropology and Art Practice (Bloomsbury, 2013), e com Caterina Pasqualino Experimental Film and Anthropology (Bloomsbury, 2014), é possível acompanhar o

1. Esse trabalho contou com o apoio da Fundação de Amparo à Pesquisa do Estado de São Paulo (FAPESP processo $n^{\circ} 2016 / 05318-7$ ). 
desenvolvimento deste campo que intersecciona arte contemporânea, filme e antropologia, com ênfase na prática e na colaboração.

Esta entrevista foi realizada na Itália, em Castiglioni del Lago, durante o Seminario Internazionali di Antropologia Visiva, em outubro de 2018, coorganizado pelo Laboratorio Ars Videndi- Dispoc da Università di Siena, pela Scuola di Specializzazione in Beni DEA Università di Perugia e pelo Laboratório de Imagem e Som em Antropologia, da Universidade de São Paulo. Durante três dias, estivemos entre antropólogos que de formas diversas constroem suas pesquisas a partir de empréstimos e trocas com artistas. Nós também, os autores da entrevista, temos experimentado as conexões entre antropologia, filme e música, e nessa conversa com Schneider falamos de uma antropologia visual que se abre para outros sentidos além da visão, do aprendizado da "linguagem disciplinar" do outro, e da ideia de uma escola que forme antropólogos-artistas. 0 trabalho de Schneider é em si uma prática que demonstra o potencial do alargamento das fronteiras disciplinares, e a riqueza teórica e analítica que emerge do trabalho colaborativo nos interstícios.

JASPER: Um termo é capaz de definir uma área de atuação? Você sugeriu que antropologia visual não é um termo apropriado. Deveríamos estar falando em antropologia sensorial, ou em antropologia sonora e visual?

ARND: Bem, não sei se eu disse que é um equívoco falar em antropologia visual, mas certamente é agora um campo muito mais amplo, porque possui todos esses elementos. Inclui, obviamente, aspectos sensoriais. 0 visual em si é um de nossos sentidos: a visão. Porém, o visual vai muito além do que possivelmente assume-se como visão, que remeteria apenas à percepção através de nossos olhos. De fato, falando sobre cinema, no livro The Skin of the Film (1999), Laura Marks introduziu o termo visão háptica, que implica que, quando vemos algo, outros sentidos estão também envolvidos. Este aspecto é bem óbvio no cinema, na percepção de projeções cinematográficas. É só pensar sobre Um cão andaluz (Un Chien Andalou, 1929), o famoso filme de Luis Buñuel, onde um olho de bezerro é cortado com uma navalha. Claro que, naquela narrativa em particular, a intenção é representar um olho humano (mostrado pouco antes do corte, com uma navalha ao seu lado), e a sensação que provoca, até mesmo quando conversamos sobre o episódio agora, é certamente uma espécie de abalo interior, como se algo assim estivesse realmente acontecendo com um ser vivo. Esse é um exemplo óbvio, mas muitas outras sensações hápticas podem ser produzidas. Pensando somente sobre como os sentidos são classificados (e isto é historicamente contingente no Ocidente), nós podemos acrescentar o sentido do olfato, e não somente como ele recentemente é usado no cinema - onde é possível evocar cheiros ou até ter efeitos olfativos na sala - mas também como o cheiro pode ser evocado por certas imagens. Mas além disso, em outras 
culturas, mas também no nosso conhecimento da experiência sinestésica, isso é onde os sentidos se entrecruzam. E isso pode ser induzido tanto por imagens particularmente fortes, quanto, em outras culturas, com a ajuda de alucinógenos, ou através de rituais particulares, ou pela prática do transe. Então, há muitas coisas a serem consideradas quando falamos sobre um campo ampliado de antropologia visual.

JASPER: Obrigado. Gostaria de voltar a algo sobre o que conversamos ontem, porém nós não levamos para este rumo, que são as incomensurabilidades ontológicas. Quais são as incomensurabilidades entre arte e antropologia como você as vê agora, alguns anos após ter iniciado essa linha de pesquisa?

ARND: As incomensurabilidades? Sim, certamente eu usei esse termo para falar sobre os assuntos/temas (subject) da disciplina, se você preferir, frequentemente chamados de objetos, mas que de fato são sujeitos, porque eles participam na pesquisa, de certa forma o outro que nós estamos investigando. Portanto, em termos de diferença cultural, obviamente, o problema da alteridade ou da incomensurabilidade, em sua formulação definitiva se você preferir, é postulado: é onde termos não podem ser traduzidos, onde é preciso interromper a tentativa de entender e simplesmente aceitar ou considerar, e ter em vista a posição do outro. Marisol de la Cadena, em um livro recente, Earth Beings (2015), mas também em outras obras, introduziu o termo os incomuns (the uncommons). Com os comuns, e isto vem de um debate político, frequentemente associamos termos que se referem à recursos, os quais nos preocupam no planeta, uma vez que são finitos, limitados no ambiente: água, e qualquer outro recurso natural. Porém, os incomuns no sentido ontológico também são elementos de outra 'cultura', de um modo de pensamento, de uma cosmologia, que não pode ser traduzida. No discurso político, isso às vezes produz dificuldades - isso é o argumento de Marisol de la Cadena - até quando agências bem intencionadas, como ONGs, ou pessoas que em solidariedade se compadecem com as dificuldades, por exemplo, de povos indígenas, tentam negociar com outros agentes, agentes poderosos do governo e de multinacionais. Porque povos indígenas, e, no caso dela, falantes de Quéchua no Peru, introduzem outros agentes, por exemplo, as montanhas, que são introduzidas no debate. E como negociamos isso? Ou como devem saber, na Nova Zelândia certas montanhas foram reconhecidas como pessoas jurídicas, o que quer dizer que se você fizer algo a elas, se danificá-las, é o mesmo que causar danos a uma pessoa, a um ser humano. E é claro que isso é completamente diferente do que chamamos de destruição ou intervenção, ou uma intervenção irreparável no ambiente, porque nesse caso há o conceito de pessoa.

Agora, na medida em que interessa transferir esse pensamento para arte e antropologia, significaria que temos que respeitar as diferenças uns dos outros. E as diferenças são de um lado talvez ainda metodológicas 
em antropologia, mas possivelmente, e isto é bem interessante, também éticas. Não porque a antropologia tenha o privilégio de uma posição ética, pelo contrário, por nossa história colonial nós aprendemos de certo modo, ou tivemos que aprender, como lidar com a ética porque nossos padrões éticos estavam comprometidos. E não apenas colonial, mas também pós-colonial, se você pensar em antropólogos e cientistas sociais que colaboraram na Guerra do Vietnã e foram colocados pelos americanos em campanhas militares, mas também em outros lugares. Sendo assim, por exemplo, a Associação Americana de Antropologia, que se distanciou de tais ações, desenvolveu, assim, um certo código para práticas éticas, como muitas outras associações antropológicas. Quando lidamos com pessoas, estamos cientes de coisas [éticas] muito simples como antropólogos visuais: como pedir permissão para quem estamos entrevistando, fotografando ou filmando. E também posteriormente deixarmos o material de pesquisa disponível para o acesso, para que seja realmente uma iniciativa colaborativa e participativa.

Agora, no que diz respeito à arte, esse discurso ético é um tanto diferente, não pelo que eu disse sobre antropólogos serem pessoas mais éticas, mas, pelo contrário, porque a ética não é codificada dessa forma. E às vezes, artistas, deliberadamente, com o intuito de tornar visível a contingência histórica ou particular da ética no momento, ou de sistemas éticos, os transgridem. Então, artistas (não estou dizendo às vezes ou sempre) transgridem [a ética]. Assim, você pode pensar na arte do Acionismo vienense [Viennese Actionists] dos anos 60, que usava sangue, corpos nus, e destruição violenta, ou em outros artistas que trabalharam, por exemplo, em um questão particularmente árdua, que é a representação ou não do Holocausto, ou de outros massacres ou atrocidades, e assim por diante. E, às vezes, artistas transgridem os parâmetros éticos da sociedade precisamente para torná-los visíveis, o que nós em antropologia não podemos mais fazer. Portanto, há também uma discussão a ser feita, e há talvez uma certa alteridade nesse sentido.

Eu poderia citar as alteridades mais óbvias, mas elas são aquelas mais convencionais, e penso que elas foram um pouco suplantadas. Elas sugeririam que o antropólogo é a pessoa mais sistemática e metodológica, enquanto que o artista tem uma abordagem mais subjetiva, uma visão mais individualizada e poética em sua pesquisa. Mas eu acredito que na realidade a diferença ou a alteridade entre ambos não é tão rígida como seria no caso da ética, mas isso se deve a uma história particular da antropologia. E, claro, não se aplica para todas as artes, mas apenas quando se observa uma obra de arte e às vezes um ato de transgressão ética que aparenta ser gratuito para um leigo, representa uma finalidade específica justamente para dar visibilidade à ética. Mas, em antropologia, em uma antropologia mais arriscada, não seria apoiada pela maioria dos antropólogos. Possivelmente existem pessoas que fazem isso... 
JASPER: Artistas possuem maior agência que antropólogos?

ARND: Sim, talvez poderíamos resumir dessa forma.

JASPER: Mais tipicamente, você fala em seus livros sobre como a antropologia institucionalmente teve um problema com a beleza, com a ideia de que não podemos fazer práticas artísticas como método de pesquisa porque isso é de certa forma mais subjetivo. Estaríamos nos afastando do que define nossa disciplina, nossa área precisa ser talvez um pouco mais estruturada. Mas eu vou perguntar [algo diferente], sobre a popularidade global dos Cubos Brancos e a bienalização do mundo da arte, e como você acredita que isso impactou a forma como a alteridade é representada nos casos muito bem conhecidos por você, por ter trabalho com antropólogos e artistas que atuam entre esses espaços. Como isso muda a dinâmica de prática representacional?

ARND: Sim, eu certamente concordaria [sobre a mudança na dinâmica das práticas representacionais], ou sobre o que nós agora chamamos de sistema de arte, mas é talvez um fenômeno historicamente contingente, que agora se globalizou. Essa é a forma como a obra de arte está comunicando e esse é o tipo de conjunto de parâmetros ou estrutura que ela está utilizando para se auto representar. Em termos de encontro histórico entre arte e antropologia existe o exemplo da França na década de 1930, quando os Surrealistas criaram em torno de uma revista em particular, Documents, um discurso muito fértil sobre colaboração, diálogo, intervenções comuns, e também sobre representações. Mas, isso não estava correlacionado a um mundo artístico em particular, apesar de certos artistas terem participado de sua elaboração. Em vez disso, naquele momento, estava conectado às instituições como o recém fundado Musée de l'Homme em Paris, o Instituto de Sociologia e assim por diante, e a certas pessoas, algumas das quais ganharam ainda maior notoriedade depois da Segunda Guerra Mundial. Mas isso foi em um tempo em que ainda não havia uma figura particular que agora se tornou bastante proeminente no mundo da arte global do Cubo Branco: o curador. Curadores agora são basicamente os guardiões do que está acontecendo no mundo da arte, a meu ver. E eu não digo isto no sentido negativo, mas no sentido de que eles são quase como antropólogos. Eles estão rondando o mundo da arte, ou o que está por lá em termos de produção etnográfica, e tentando se apropriar disso, e então apresentar isso em certas localidades. Então, os curadores permanentemente empregados na galeria estadual, institucional ou municipal - o cenário que nos é familiar até os anos 60 e início dos anos 70 - ainda existem, mas são antes uma minoria. Até mesmo essas instituições agora contratam curadores de fora e freelancers. Alguns deles muito talentosos, muito interessantes, e isso também permitiu a inclusão de pontos de vista globais, se você pensar no papel proeminente que o falecido Okwui 
Enwezor teve, por exemplo sendo o curador da Documenta 11, da Bienal de Veneza, mas também da exposição 'Intense Proximity' (2012) no Palais de Tokyo, como orador na Bienal de Dakar, dentre muitas outras coisas. 0 mundo dos Cubos Brancos do cenário contemporâneo de arte tornou-se o assunto de pesquisas etnográficas e de bienais. Meu colega Thomas Fillitz, da Universidade de Viena, escreveu sobre as Bienais de Dakar e sobre a posição dos artistas africanos nelas, mas existem agora muitos trabalhos que investigam mundos da arte. Isso iniciou-se em Stockholm e outros lugares, mas agora existem muitos estudos de mundos de arte 'local' / 'global', incluindo o Brasil. Sim, eu acho que o sistema dos Cubos Brancos é um fator importante a ser levado em consideração.

ROSE: Eu gostaria de perguntar sobre o estado da arte dessas colaborações, diálogos e abordagens entre antropólogos e artistas, e em sua própria experiência como têm sido as colaborações, abordagens e diálogos entre você, como antropólogo, e artistas?

ARND: Sim, obrigado pela pergunta. Neste momento eu gostaria de introduzir brevemente o termo hermenêutica desigual (uneven hermeneutics) sobre o qual eu falei ontem. Isso vem de um pensamento que foi introduzido anteriormente como "termos de fala" ["speaking terms"], que James Clifford usou para caracterizar essa colaboração histórica dos antropólogos e artistas surrealistas na década de 1930. Agora, eu penso que esse termo deve se tornar produtivo, deve ser preenchido de conteúdo no presente, e isso é o que está acontecendo a partir das colaborações entre artistas e antropólogos. É por isso que eu também - e isso toca novamente a primeira questão - fico relutante em dizer como ambos são diferentes, porque essas diferenças são por um lado relacionais. Elas devem ser estabelecidas em um diálogo no presente, assim que exista um interesse comum ou uma área de investigação, assim como aconteceu entre mim e Leone Contini em um projeto recente, o projeto de exibição partindo do projeto TRACES Horizon 2020 da União Europeia sobre patrimônio cultural contestado (www. tracesproject.eu). E juntamente com o artista Leone Contini, nós investigamos o patrimônio colonial enterrado no Museu Etnográfico Nacional de Pigorini, em Roma. Mas, como nós colaboramos, e como nós conseguimos colaborar com os curadores no museu, e depois com nossos entrevistados, idosos ítalo-líbios, colonos italianos, que foram expulsos da Líbia em 1970 por Gaddafi? Isso depende de acordos, você não pode definir os termos em questão, é na base de conversa que você os descobrirá. Hermenêutica desigual também significa que é preciso ter em conta as diferenças. Nesse caso, nós todos estávamos operando em um contexto de primeiro mundo. Mas, é claro, o tópico também incluiu outras partes do mundo, de modo que devem ser levadas em consideração. Entre estes participantes não haviam diferenças essenciais, apenas um grau muito leve de poder, status, classificação, educação e assim por diante. De qualquer forma, não de maneira 
tão pronunciada quanto eu experienciei ao trabalhar na Argentina, quando colaborei com artistas na província do nordeste de Corrientes, na fronteira com o Paraguai. Foi lá, com artistas da escola de arte local, que eu rapidamente, e através de uma curva de aprendizado íngreme, descobri que eles vieram de origens completamente diferentes. Tanto em sua compreensão da antropologia, como também nos termos em que praticavam arte (ou o que de fato eu entendia). E talvez eles possuíssem diferentes expectativas sobre o projeto, porque o que realmente os interessava era que suas obras de arte entrassem no mundo da arte argentina e se tornassem reconhecidas. Enquanto que, para mim, eu queria informações sobre a metodologia deles, e como eles trabalhavam como artistas, e como eles se relacionavam - como eram eles mesmo daquela parte da Argentina - com a população local. E nas entrevistas que eu reproduzi neste artigo, primeiro no Critical Arts, e agora uma parte eu reproduzo em um artigo recente do Field Journal, (1) torna-se claro que eles de fato me dizem: "você estava nos usando como tradutores, você estava nos usando como condutores para sua pesquisa antropológica”. Deste modo, há uma cobrança direta nessa fala, sobre eu estar usando-os, e também sobre eu ter uma formação diferente, que isso era para o benefício da academia, mas o que eles ganhariam com isso? Isso deve ser negociado, e mesmo assim, nesse caso, nós continuamos, fizemos uma coprodução, ela teve sua parte contestada. Mas, às vezes, tais projetos devem ser abandonados, ou não podem ser levados adiante, ou são levados até metade do caminho. No início você não é capaz de saber.

JASPER: Como você aconselha seus estudantes para serem capazes de tomar esse tipo de decisão?

ARND: Bom, isso nos leva basicamente para a ética que eu apontei anteriormente. Eu acredito que, como antropólogo, em qualquer projeto é preciso aprender a língua em vários sentidos. Isso significa tanto a linguagem do lugar, mas também, se você colaborar com artistas, a linguagem disciplinar do outro. Você não pode chegar com presunções tais como a de que 0 artista é menos instruído, talvez menos instruído academicamente, menos treinado academicamente, ou que não tem conhecimento antropológico, ou tem um modo menos sistemático de proceder em sua pesquisa artística, por exemplo. Frequentemente, esses têm sido os preconceitos estabelecidos e difundidos em antropologia. É de fato bem visível em diversas discussões em torno de obras clássicas de antropologia visual, se recordarmos da discussão nos anos 80 sobre o filme Forest of Bliss (1986) de Robert Gardner, sobre a vida cotidiana em Benares (Índia), incluindo ritos funerários, assim como outros de seus trabalhos. Estas foram investigações bastante poéticas de outros mundos e de outras cosmologias, mas para especialistas da antropologia destas áreas do mundo foram trabalhos muito atacados, e a antropologia visual foi acusada de não ser analítica, de não ser etnograficamente fundamentada da mesma maneira. Mas eu acho que antes de 
fazermos isso, nós temos que entender a caixa de ferramentas e também o pensamento do outro. Neste contexto, o outro disciplinar. Isso traz, é claro, o terceiro assunto, que são, nesse caso, as pessoas com quem estamos trabalhando na área, se é esse tipo de antropologia.

ROSE: Sobre essas duas formas - artistas em relação à antropologia e antropólogos em relação à arte - você acredita que o interesse se apresenta ainda mais por parte de artistas em antropologia do que o contrário?

ARND: É difícil de afirmar, isso remete a um debate, a um artigo de Foster, o qual tornou-se muito influente: "The artist as ethnographer". É frequentemente citado, e corretamente, a partir de uma das antologias dos escritos de Hal Foster (The Return of the Real 1996). Entretanto, foi publicado como um artigo em uma importante coleção de dois antropólogos, George Marcus e Fred Myers, The Traffic in Culture (1995). Basicamente Foster argumenta - eu acredito que ele estava certo - que no que foi chamado de virada etnográfica nas artes, na década de 1990, as incursões de artistas no campo etnográfico eram, por vezes, apenas para obter uma maior exposição no mundo das artes e para o avanço de suas próprias carreiras. E vice-versa, claro. Então, por parte também da antropologia, há o que foi chamado de "inveja do artista" ou "inveja do antropólogo" em relação às artes. A ideia de que nós, talvez, gostaríamos de ser tão bons quanto, de que nós vemos as limitações de não termos sido treinados nessa área, de ter apenas habilidades de escrita e analíticas, e que gostaríamos pelo menos de ter potencial para desenhar bem, e talvez até de pintar ou fazer esculturas, pensando somente em formas de arte visual bem clássicas (ainda não superadas, apesar de não podermos somente pensar nessa compartimentalização). E além disso, é claro, a imagem em movimento da filmagem ou a fotografia, somente para mencionar alguns gêneros. Nós gostaríamos de ser muito bons uma vez que nos abrimos e expandimos para dentro dessas áreas. $\mathrm{E}$ temos inveja de praticantes que aprenderam isso e que também têm talento, têm feito isso há muito tempo, e aperfeiçoaram essas técnicas e habilidades. Mas eu acredito, pessoalmente, que sempre foi uma questão de colaboração, onde eu acho que se trabalha através destes limites. É claro que existem outros, como o notável Tim Ingold, o qual argumentou que certas formas de prática, como desenhar, possuem um valor em si também para antropólogos. Mesmo que elas não alcancem o grau de virtuosidade, de domínio, de maestria, como um artista alcançaria, elas possuem outras qualidades e características intrínsecas, o que as tornam úteis para antropólogos. Então, sim, idealmente eu também sonho com uma escola (talvez o seu departamento no Brasil seja uma delas, certamente em termos de câmera, ambas fotográfica e em movimento), um departamento ou um ambiente interdisciplinar onde pessoas possam ser treinadas em diferentes áreas e habilidades, a fim de que se tornem artistas-antropólogos. 
(1) Schneider, Arnd "Contested Grounds:

Reflecting on Collaborations with Artists in Corrientes, Argentina", Critical Arts, 2013, 27 (5), 511 - 530;

Schneider, Arnd "Between Uneven Hermeneutics and Alterity: The Dialogical Principle in the Art-Anthropology Encounter", FIELD: A Journal of Socially Engaged Art Criticism, http://field-journal.com/issue-11/between-uneven-hermeneuticsand-alterity-the-dialogical-principle-in-the-art-anthropology-encounter

\section{RESUMO}

O antropólogo Arnd Schneider aborda nesta entrevista algumas questões em torno das relações entre arte contemporânea, filme e antropologia, campo explorado em diversos livros e eventos que tem organizado desde o início dos anos 2000. Sua ênfase se dá nas práticas de colaboração entre artistas e antropólogos, e no alargamento das fronteiras disciplinares.

\section{ABSTRACT}

In this interview the anthropologist Arnd Schneider addresses questions about the relations between contemporary art, film and anthropology, a field explored in several books and events that he has organised since the early 2000s. He emphasises collaborative practices between artists and anthropologists, and the widening of disciplinary boundaries.

JASPER CHALCRAFT é pesquisador (Jean Monnet Fellow) no Robert Schuman Centre for Advanced Studies no European University Institute (Florença, Itália). Trabalha atualmente em dois projetos: um deles foca em como trabalhar com o 'patrimônio difícil' na Europa, o outro no ativismo cultural de novos imigrantes africanos em São Paulo, Brasil. Trabalhando com profissionais do setor como membro do projeto "Heritage Contact Zone", financiado pelo Creative Europe, tem explorado modos práticos de trabalhar com o patrimônio contestado, desde a inclusão cultural de minorias na Europa, até a nova diplomacia cultural em torno do patrimônio em risco. E-mail: diaspro1@gmail.com

ROSE SATIKO GITIRANA HIKIJI é professora do Departamento de Antropologia da Universidade de São Paulo. Vice-coordenadora do Laboratório de Imagem e Som em Antropologia, coordena o PAM (Pesquisas em Antropologia Musical). Autora dos livros Imagem-violência, A música e o risco, Lá do Leste, co-organizadora de A experiência da imagem na etnografia, Antropologia e Performance, Escrituras da Imagem e Imagem-Conhecimento. Co-diretora de Woya Hayi Mawe, Tabuluja, Violão-Canção, Fabrik Funk, A arte e a rua, entre outros filmes etnográficos. É bolsista de produtividade do CNPq 309705/2016-9, e realiza pesquisas com Jasper Chalcraft, com apoio da Fundação de Apoio à Pesquisa do Estado de São Paulo (FAPESP Processos 2016/05318-7 e 2019/09397-7). E-mail: satiko@usp.br

Contribuição de autoria. Jasper Chalcraft e Rose Satiko G. Hikiji: concepção, elaboração do manuscrito, redação, discussão de resultados.

Licença de uso. Este artigo está licenciado sob a Licença Creative Commons CC-BY. Com essa licença você pode compartilhar, adaptar, criar para qualquer fim, desde que atribua a autoria da obra. 